\title{
Greasing the Wheels: Invisible Labour in Interdisciplinary Environments
}

Kimberley Staines and Harriet Martin

\begin{abstract}
This chapter investigates what is meant by work in the context of an interdisciplinary environment, asking which work is visible and which work remains invisible. Kimberley Staines's and Harriet Martin's starting point has been to understand their respective roles as project managers and performers within such a context. They go on to explore the rhythms and temporalities of the interdisciplinary practice they have participated in, and they argue that large-scale collaborative research projects might be better served by identifying - making visible - the invisible labour required for such research to take place.
\end{abstract}

Keywords Collaboration · Emotional labour · Interdisciplinarity · Invisible labour · Performative labour · Rhythms

\footnotetext{
K. Staines $(\square)$

Durham University, Durham, United Kingdom e-mail: staines.kimberley@gmail.com

H. Martin

Wellcome Trust, London, United Kingdom e-mail: H.Martin@wellcome.ac.uk

(C) The Author(s) 2016 


\section{The Participating Non-Academic}

As Hubbub Projector Coordinator at Durham University and Hub Partnership Manager for Wellcome, respectively, we both work in multifaceted posts requiring diverse skills. We are both key participants in Hubbub, with influence over the programme of work and responsibility for resource management, people management, finance and event production via our respective organizations. Both roles are rooted in routine administration and communication, both of the exciting, attention-grabbing, external kind, and the more sensitive, internally-focused kind, which is aimed at motivating teams and navigating a path through difficult issues. We both hold responsibility for ensuring the effectiveness of The Hub as the physical base of the Hubbub experiment.

The distinction between our roles is that the Project Coordinator sits right at the heart of Hubbub, working closely alongside the Principal Investigator and core group, keeping an eye on the development of the project and establishing inventive ways to make a university-governed project run effectively at a distance from the university itself. The Hub Partnership Manager, meanwhile, is a role existing between the funder and funded group, working across Hubbub and Wellcome to realize potential collaborations and opportunities to share learning and expertise. We refer to both roles with the collective 'project manager' throughout this chapter.

Having established the positions we inhabit within the project - officially not researchers, but both clearly deeply entrenched in the social dynamics, intellectual questions and practical mechanics of the project - we consider how the role of the 'non-academic' fits within a large-scale research group. Within Hubbub, this discussion is particularly tricky. The project is aimed not just at creating new research, but at opening up the practices of different researchers within a collaborative, interdisciplinary environment. This requires adopting novel ways of interacting with one another, as well as a significant amount of thought and emotional labour on the part of the designers of the Hub/Hubbub experience (in this case, emotional labour describes the ongoing prioritization of the well-being of other collaborators on the project, through acts of facilitation, amelioration and continuous social engagement). It can be a struggle for a 'non-specialist' (where specialist is an individual bringing expertise within a recognized academic research discipline) to find a place within the project in a way that ensures both autonomy and influence, and remains meaningful for 
the individual carrying out that role. This can be further complicated when the non-academic, by merit of their centrality to the project, experiences increased demand for their counsel and increased opportunities to contribute directly to research discussions - a form of necessary, yet frequently unacknowledged collaboration. And as the practice of supporting, managing or facilitating is, though critical, not deemed a 'discipline' as such within this context, this significant labour can fly under the radar.

Ken Arnold, in his foreword to this book, draws our attention to a unique identifying feature of Hubbub: the 'attentive introspection' taking place in The Hub. This occurs as researchers gather to contemplate the shared theme of rest through a process of opening up their practices to external examination, identifying difference, commonality and neutrality between the practices, and challenging commonly held assumptions. An important question is at stake here: what are the barriers put up by language - specifically academic discourse - in this process? It is important to acknowledge the hard reality that one can remove researchers from the academy, but it is less straightforward to remove academia from the academics. These complexities do not simply affect the project managers: Hubbub includes collaborators from many classically non-academic backgrounds, including public engagement, media production and youth work. How do we allow for a level access point to conversations, and enable these to move beyond introspection towards unpicking a shared research question? And how do we ensure recognition of the extensive technical labour - shared by academics and non-academics - that goes into the process of taking apart and reconstructing a shared discourse, to try to ensure that such labour can be appropriately planned for and, crucially, recognized?

\section{Institutional Rhythms And ArRhythmias}

Hubbub's collaborators are based in various locations within and outside the UK. Of the group's collaborator network of over 50 people, only three work full time on the project. A further small number are employed by Durham University, while numerous other complicated relationships exist between collaborators and the project, owing to the mixed nature of research strands falling within the Hubbub programme.

As grant holder, Durham University holds the majority of Hubbub's administration, but Hubbub's base at The Hub within Wellcome Collection means that members of the group work closely with colleagues 
at Wellcome. As Wellcome Collection is a public cultural venue responding to the interests of its visitors, the work that takes place in collaboration with Wellcome can require a quick turnaround. Hubbub occupies a conflicted space in that respect, as the group's day-to-day rhythms and patterns of movement echo those of Wellcome staff. However, the university structure, which governs all contracting and procurement elements of the project, has different rhythms from Wellcome, which means the project does not navigate every situation as Wellcome would, and concessions have to be made which impact patterns of work and activity.

\section{Performing Research and the Visibility of Labour}

In academia, a tension exists between visible and invisible working practices and people. The tension lies, firstly, in the type of labour being undertaken (recognizing that in academia a research output, preferably peer-reviewed, is prized above all else); secondly, in who is carrying out the work (this is not about individual identity, but rather the role a person performs on a research project, typically either as an academic or as support staff, although we acknowledge this binary is not exhaustive). These are two distinct scales - labour and roles - and it's important to note that all roles have their own forms of visible and invisible labour.

To explain what is meant by the type of labour, work might be placed on a spectrum where visibility increases the closer you get to a finished research output (publishing an academic paper), and invisibility means being 'behind the scenes' and distant from that output (pulling together a budget forecast, for example). To explain what is meant by who is carrying out the role, the researchers delivering the outputs and performing experimental objectives might be considered outwardly visible; by contrast, those not tasked with delivering research-specific outputs (the support staff) become invisible.

But in an interdisciplinary space like The Hub, this idea is turned on its head. Hubbub is an experiment in collaborative interdisciplinary working; an environment in which the network must be seen to be active, and for those within it, must feel active, to provide a sense of assurance to all that the experiment is unfolding as it should. Under scrutiny, interactions also become forms of output: invisible work becomes highly visible. Where the visible workers (researchers) have invisible work to do (e.g. exploratory,

\footnotetext{
i See also Foreword.
} 
non-directed reading) which diverts their attention from performing interactions, the invisible workers (project managers, support staff) become visible, stepping up and performing within the space to ensure action is seen to be unfolding and connections are seen to be being made. The act of a project manager contributing towards a research output - in the case of this book, for example - renders a role which is typically invisible, suddenly visible.

We acknowledge that these distinctions are far from clear cut in reality. But the tension of 'performing interdisciplinarity' lies in how these typically unspoken distinctions are blurred within this refreshingly atypical working environment. On a daily basis, a player within the space may ask themselves: At which point is one obliged to perform, and at which point should one defer that performance? ?i $^{\text {i }}$

Specific questions spring to mind as conversations surrounding this labour unfold: In a collaborative interdisciplinary project made up of academic and non-academic staff, who is entitled to certain kinds of rest? This rest might consist in stepping back from the hosting and facilitation of play - for example, by not attending an exploratory workshop outside one's specific discipline and without any immediate output in mind - in order to focus on an individual task. Or it might mean having the choice not to turn up for-perform at - a social event that serves as a kind of glue in the matrix of interdisciplinary collaboration. To what extent does the response to this question hinge on the value attributed to the work carried out by a specific individual? Is the most visible (or perhaps valuable) worker ultimately the individual whose hand is closest to the creation of a finished product, that is, an academic output? Can that be correct? Should it be correct? We must recognize that a social hierarchy can often be at play here.

Given, also, that this is a book and a project about rest, restlessness and all the spaces in between, it seems not inappropriate to point out that invisible labour - that of engaging and updating stakeholders, facilitating social bonds, maintaining goodwill, enabling playfulness, picking up the slack and making sure nothing is forgotten - carried out by university administrators, project managers and researchers alike (in fact by anyone trying to organize or get anything done, anywhere, and in particular where others are relying on them) is unrelenting, yet remarkably easy to overlook. From a project manager perspective, the Hubbub/Hub experiment has proved fertile ground for thinking about these questions - prevalent across so many work spaces - and for addressing them head on.

iiSee Chap. 19. 


\section{WHAT Now?}

When fulfilling a function not typically part of the research process, it can feel contrived to attempt to establish oneself on an even footing alongside academics; but there are, we believe, crucial roles for the non-academic to play in this context. They are that of the sounding board, the host, the advocate, the ambassador; the practical heads who ensure an accessible gateway into interdisciplinary conversations exists. This type of work is both informal and deeply personal. It requires a respectful handling of complex situations and can be exposing and alienating. Without a doubt, it is wholly necessary within an interdisciplinary environment.

One of the challenges is how best to expose this process: to open up the invisible practices that support experimental work, and understand how this work can be recognized and expanded upon. How can we properly identify and credit labour in an interdisciplinary space, and how might the academy further support experimental practice, leading the way in developing a framework for interdisciplinary practice?

Acknowledgements With thanks to our many colleagues across Hubbub, Wellcome and Durham University whose advice and listening ears we've relied on over the course of the project. A particular thanks to all those who've provided invisible assistance within The Hub while we've laboured, including (but certainly not limited to) Annelise Andersen, Sophie Durrans, Elena Gillies, Imô Otoro, Charlotte Sowerby and Louise Tolton.

\section{FURTHER READING}

Callard, Felicity, and Des Fitzgerald. Rethinking Interdisciplinarity across the Social Sciences and Neurosciences. Basingstoke: Palgrave Macmillan, 2015.

Delbridge, Rick, and Jeffrey J. Sallaz 'Work: Four Worlds and Ways of Seeing'. Organization Studies 36, no. 11 (2015): 1449-62.

Frayne, David. The Refusal of Work: Theory and Practice of Resistance to Work. London: Zed Books, 2016.

Patton, Victoria. 'People \& Roles: The Project Coordinator'. Working Knowledge: Transferable Methodology for Interdisciplinary Research, 2015; http://www. workingknowledgeps.com/wp-content/uploads/2015/03/WKPS_Proj_ Coord_Final.pdf.

Russell Hochschild, Arlie. The Managed Heart: Commercialization of Human Feeling, 1983. 2nd ed. Berkeley, alif. and London: University of California Press, 2012. 
Kimberley Staines is Project Coordinator of Hubbub, employed by Durham University. She has a background in law and publishing, is a Master's student in Psychosocial Studies at Birkbeck, University of London, and is a trustee of a food bank in London.

Harriet Martin is Partnership Manager for The Hub at Wellcome Collection where Hubbub was in residence from 2014 to 2016. Her background is in leading large-scale public engagement initiatives, public programming and project management for a range of museums, universities and charities in Bristol and London.

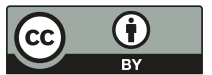

This chapter is distributed under the terms of the Creative Commons Attribution 4.0 International License (http://creativecommons.org/ licenses/by/4.0/), which permits use, duplication, adaptation, distribution and reproduction in any medium or format, as long as you give appropriate credit to the original author(s) and the source, a link is provided to the Creative Commons license and any changes made are indicated.

The images or other third party material in this chapter are included in the work's Creative Commons license, unless indicated otherwise in the credit line; if such material is not included in the work's Creative Commons license and the respective action is not permitted by statutory regulation, users will need to obtain permission from the license holder to duplicate, adapt or reproduce the material. 